\title{
A Study on C-E Translation of Product Introductory Texts on Company Websites Under Skopos Theory
}

\author{
ZHANG Man, CHEN Xiao-xiao \\ Guangdong University of Foreign Studies, Guangzhou, China
}

\begin{abstract}
This paper takes the C-E translation of product introductory texts on official websites of three mobile phone makers as the study object under the Skopos theory, with an aim to identify and analyze the distinctive translation features of such special type of text. The exhausted parse and analysis bring out the findings that there exists a significant translation difference between the Chinese and English-version product introductory texts on official websites. It is found that Chinese introductory texts are more inclined to rely on exquisite words and redundant expressions to describe products' features and functions, while switching to the corresponding English version, simple vocabularies and compact sentence structure are more frequent. Hereafter, this paper raises two practical guidelines to instruct translation activities in business contexts.
\end{abstract}

Keywords: Skopos theory, product introductory texts, company website, C-E translation

\section{Introduction}

With the increasingly mature development of technology, a growing number of Chinese local phone makers have already emerged in the international market. Thanks to the internet, visiting enterprise websites nowadays has gradually become a convenient approach to get some information about the product or service portfolio of one enterprise for customers far away. Potential customers in overseas target markets can view products they have interests in through the official website of enterprises, then make comparison and final choice whether to buy or not. In order to effectively attract customers' eyes and motivate their purchase desire, product introductory texts, as one kind of foreign publicity materials of enterprises, must be of premium-quality. On this basis, how to correctly create website content, effectively promote products, and win the trust of overseas target customers turn out to be one of the key factors that determine the success of enterprises in the international market. For Chinese phone vendors targeting to operate well in overseas markets, it is of great significance to break through the obstacle of language and culture and transmit accurate and effective information of electronic products across borders by means of C-E translation of web product introductions. From the perspective of Skopos theory, this study conducts systematical and qualitative analysis on the C-E translation of product introductory texts on Chinese technology enterprises' websites. Through a case study of the introductory texts of three latest mobile

ZHANG Man, graduate student, School of English for International Business, Guangdong University of Foreign Studies, Guangzhou, China.

CHEN Xiao-xiao, Professor, School of English for International Business, Guangdong University of Foreign Studies, Guangzhou, China. 
phones issued in 2018 by three technology enterprises respectively, it is found that the purpose of publishing product introductory texts is to achieve the greatest publicity effect through the translation of product introductory texts, which is characterized by "best publicity validity", while the translated-version introductory texts give full consideration to overseas customers who would have much expectation to obtain maximum information disclosure. Therefore, this study holds that the translation of product introductory texts shall cater for the psychological expectations of both enterprises and their target customers.

This study seeks to provide operational guidance for the translation of enterprise product introductory texts by making efforts to establish the theoretical category system of translation strategies, thus helping Chinese enterprises to use more accurate and appropriate English translation to smoothly and effectively convey relevant information of scientific and technological products to the target market in the process of "going globally" so as to attract more customers from overseas markets.

\section{Relevant Researches on Foreign Publicity Materials of Enterprises}

In recent years, the translation of Chinese corporate publicity materials in webpages has attracted the attention and interest of some researchers. There are already many researches to explore the translation strategies of corporate publicity translation from the perspective of Skopos theory, translation variation theory, reception theory, and text type theory. In addition, there are also some articles describing various translation errors in the English translation of Chinese corporate publicity materials (Lu, 2012). All in all, most of scholars aim at company profiles as their research subjects, to a certain degree giving relatively less attention to product introductory texts which are also showcased in corporate webpages as a kind of corporate publicity material. According to Newmark (2001), all texts fall into three categories: expressive texts, informative texts, and vocative texts. Corporate publicity text belongs to vocative text, the purpose of which is to let foreign readers or consumers know the enterprise in the most direct and effective way, and to publicize the enterprise image and promote products to target audiences. Moreover, seeing from the angle of Skopos theory, it argues that flexible translation methods must be adopted for specific texts to achieve the specific translation functions and purposes. Then, Christiane Nord (2001) further perfected Skopos theory and proposed specific methods for formulating appropriate translation strategies. The first principle under Skopos theory in translating texts is the purpose principle. Purpose in this case covers three dimensions: (1) the purpose of the translation process; (2) the purpose of the translation result; (3) the purpose of the translation method (Tan, 2016). Each text has its own specific purpose, to translate the text; the first step is to make clear the primary purpose, so as to determine the translation strategies and methods (Zhang, 2018). Usually, the purpose refers to the communicative purpose of translated text. In the translation process, the choice of words and expressions should conform to the culture of the target language and adapt to the aesthetic and appreciation of the target language readers. In order to achieve the purpose of translation, translators can use any strategies and methods (Sun \& Feng, 2014).

So far, most of the C-E translation studies from the perspective of Skopos theory in domestic academic field focus more on sectors such as advertisements, tourism, cosmetics, film, and television. Few studies on product introductory texts on company website can be traced. For product introductory texts translation, the aim is to publicize commodities to target consumers, thus expanding economic benefits and promote enterprise development. And how to translate the product introductory texts correctly plays a decisive role in motivating 
potential customers to purchase and helping enterprises grab more shares in the overseas markets. Therefore, this paper attempts to analyze the C-E translation of product introductory texts correctly on company websites from the perspective of Skopos theory.

\section{The Role of Product Introduction on Company Website}

Since China entered the WTO in 2001, the enabling business environment and stable political environment have given more and more momentum to corporations in varied size and government organs have formulated a large quantity of preferential policies to motivate those well-performed home companies to go globally, among which are many technology companies that have expanded their business scope to overseas markets, with the number of mobile phone shipment to foreign countries being surging according to report released by China Daily Com in November. Fueled by the international business trend, an increasing number of companies now take initiative to construct their corporate image online by establishing their own official website to showcase their business scope and product or service offerings. On the other hand, thanks to the ubiquity of internet, anyone, who has mobile phones or laptops and whether in east or west, can access to numerous information online.

Product brochure, product promotion posters, advertisement publicity, and television broadcast in the past years were viewed as the traditional means adopted by companies to market their newly developed products to the mass. While in nowadays information era featured that internet is widely accessible to general public, product introductory texts displaying on company website pages have taken the place of these traditional approaches to play an indispensably important role in bringing details about the products to the front of potential customers who have interests in the products. It serves not only as the simple introduction to specifications and features of different electronical products, but also is regarded as the promotional writings to publicity those variety of gadgets. Well-organized language expressions are fairly essential in the whole process. If sentences are lengthy and redundant in information, it's time-consuming and meaningless for potential customers, who have the expectation to catch some useful parameters about the product but fail to find them in the first sight and therefore will likely close the webpage directly and have a bad impression with the company. For electric products introduction, factors such as parameters, specifications, manufacturing materials, designs, battery capacity and life, camera pixel as well as distinctive techniques, are the primary points that need to be highlighted, for the reason that customers often pay more attention to these facets when viewing a newly introduced tool and making comparison and contrast with other competingitems. It's true for both Chinese customers and foreign clients. Attracting customers, retaining customers, and stimulating customers to pay for products are the trilogy in marketing, thus creating turnover and operational revenue. Therefore, to quickly grasp target customer's attention when he/she first comes to the homepage of the product introduction and gives his/her first sight is the most vital issue that needs emphasis.

\section{Analysis of C-E Translation of Website Product Introductory Texts From the Perspective of Skopos Theory}

A familiar scene is that Chinese product introductions are usually piled with gorgeous descriptive words in order to add poetic and pictorial effect. And it is widely accepted that Chinese texts give more focus on parataxis while English texts pay more attention to hypotaxis. Particularly in website product introduction, Chinese texts 
are quite gorgeous full of phrases and rhythmic sentences. But given the receiving habits of English readers who concern more about the concrete information, it is of necessity to make some indispensable adjustments to cater for overseas customers. In this study, the web product introductory texts of three newly issued mobile phones developed by OnePlus, Xiaomi, and Huawei have been taken as the study objects. Mobile phone introductory texts showcasing on the company websites are excerpted as follows.

\section{Refine Key Information}

Chinese people often have the tendency to add many adjective words to describe things, whether in oral presentation or written documents. The direct result aroused by such conventional behavior is redundant unnecessary information that gulfs the truly prominent clues. In a reasonable sense, customers prefer short compressed sentence containing the key information as much as possible. No one has the patience to view a webpage crowded with letters and characters. Considering the different features of product introduction, it is better to rearrange the information and content of the source text in order to decide what can be retained on the basis of the specific purposes of such introduction.

ST: 全速旗舰, 二触即发。当指纹键亮起, 拇指轻轻一触, 毫秒间, 解锁、验证, 一步到位。 (https://www.oneplus.com/cn)

TT: Unlock the speed. The OnePlus 6T unlocks the moment your finger lands on the display.

The source text uses short verbal expressions to describe the features of fingerprint unlock technology. The pauses between words and words linger much space for our readers to imagine the smooth experience. But technology texts often feature conciseness and preciseness. Through closer analysis on the ST, it is quite easy to find that the flash speed to unlock phones is the highlight that the enterprise wants to emphasize, and that is the key information the ST really wants to convey. Therefore, only the primary information of fingerprint unlock and speed are translated out in the TT, making the core feature of this type of phone more prominent.

ST: 双卡双待, 自由自在。支持两张 Nano SIM 卡使用, 你可以一个电话卡一个上网卡, 双卡之间自如切 换, 让你的生活更便捷。 (https://www.oneplus.com/cn)

TT: Double your options. Insert two SIM cards and connect to two networks simultaneously.

In the ST, the fundamental information about OnePlus $6 \mathrm{~T}$ phones is its support for two SIM cards. As for other additional descriptions, they belong to subjective comments contributed by the OnePlus company itself, instead of the scientific reviews from professional assessors, and due to the feature that subjective comments vary from mouth to mouth, lacking some trustworthy value, given this fact, the unnecessary contents are abandoned in the translation process, and the TT simplifies the core information, which chooses to tell customers that they have two choices to insert whether one or two SIM cards into the card slot just according to their own demands. For customers who are unaffordable to two sets of phones but have such demand, such type of mobile phone is the perfect option for them.

$\mathrm{ST}$ : 四曲面玻璃机身, 超轻7系铝金属中框, 水滴弧收腰设计。(https://www.mi.com/)

TT: Curved-edge glass body in a 7000 series aluminum alloy frame.

For the exterior design, the ST uses some modifiers to describe such as ultralight weight and waterdrop arc. But from the view angle of customers, they cannot measure how lightweight the phone really is just from the 
pictures showcased in the webpages. As for the phone shape, customers can have an intuitive view by seeing the phone pictures displayed on the webpages, not needing the redundant description. What they concern most might be the material used to manufacture the phone products. Therefore, when comes to the product's appearance, the used major materials are the most important part needed to be told to customers.

ST: 华为无线投屏，摆脱线缆束缚，随时随地自在分享; 影音娱乐、电竞棥速、会议沟通，均支持一键投射 到大屏幕。 (https://www.huawei.com/)

TT: Get rid of the wires. Huawei Mate 20 allows you to project presentations, gaming or video immediately to a larger screen 5 , maximizing the fun of sharing.

The ST adopted the four-character structure mainly to portray the possible situations where the phone can support the freely projection. By reading the ST in depth, we can find there are information overlapped. Therefore, at the first beginning, the TT directly gives out "Get rid of the wires", which highly summarizes the highlight of Huawei Mate 20. And the several application scenarios mentioned in the ST are briefly included into the TT, greatly shortening the sentence length and enhancing the readability while building a sound product image. And customers can get clear information from this translation.

\section{Restructure Complex Information}

For some special texts, the purpose is not only to present the translation to the target readers accurately, but also to consider whether the ultimate goal of consumers' purchase can be achieved through the translation of product introductory texts, which are sometimes viewed as the promotional texts. It's a common sense that Chinese tend to use beautiful vocabulary and symmetrical layout to organize texts for rendering our aesthetic habits, but it doesn't work for westerners, for foreign readers attach great importance to the practicability of publicity texts and the readability of information. Therefore, corporate publicity texts in English shall leave the target readers with the main impression of enterprises and products. What's more, Chinese prefer hypotaxis, whereas English gives more emphasis on parataxis; such differentiation reflects in sentences combination. Therefore, in an aim to achieve the purpose, some necessary changes should be made on sentence order to let complicated and obscure descriptions simple and understandable.

ST: 6.53英寸珍珠屏成就非凡屏占比, 沉浸视野, 震撼体验。 (https://www.huawei.com/)

TT: Be immersed by the Dewdrop display with remarkable screen-to-body ratio, supporting a full screen of distinct clarity and striking color.

The ST is aiming to spotlight its large display screen and exceptional sight experience, which are the important selling points for mobile phones. If translating the ST word by word directly, the magnificent feeling created by the two four-character phrases will be hard to reflect. The TT therefore makes adjustment on the sentence order to stress users will be immersed by a large screen, which balances the color contrast and is high-definition. Using two restrictive phrases precisely portrays the unique feature of this type of phones.

ST: 口袋里的人像影棚，为人像照片加入一缕彩虹光的期许，亦或是窗边光的静烅，让平常的一瞬间，瞬间 不平常。(https://www.mi.com/)

TT: Mi 8 is a portrait studio in your pocket. Instantly transport your portrait to the shadow under a summer tree, or beneath a window where gentle rays shine through. 
The ST depicts two artistic scenes that many people will certainly be attracted and can't help but take out cameras to take photography and record those beautiful moments. By giving such a gorgeous picture, Xiaomi seizes the momentum to unveil its distinctive camera technology that excites their both potential customers and loyal brand fans. In the C-E translation, the TT firstly uses one short sentence to highly summarize the unprecedent feature of Mi 8 camera. Customers can know what's that in the first sight. Then, in order to achieve the same expressive effect as the ST, the TT adheres to principle of fidelity under Skopos theory and develops two similar attractive application scenarios.

ST: 愈夜, 愈美丽, 悉数尽收暗夜中的每一缕光芒。AI 手持超级夜景模式, 全新的双 ISP 以及新升级的夜 景算法加持, AI 智慧防抖, 摆脱三脚架束缚, 手持即可轻松拍出令人艳慕的夜景大片。 (https://www.huawei.com/)

TT: Powered by advanced AI Image Stabilization, the Night Mode will shoot blur-free and focused handheld photos in low-light. It also balances high-contrast scenes to present incredible images in every setting.

The mixed information about phone camera of Huawei is AI-powered, handheld photography, night model. These are the three spots differentiated from other phone vendors. From the ST, it is clear to see that the sentences are in loose pattern. Due to that the uncompacted sentence pattern will lead to redundancy of expression, therefore, TT recomposes the sentence according to the inside logic order between lines, which accords with English expressive habits and writing styles.

ST: 全新银耳 $2 \mathrm{~T}$ 采用 USB Type-C 新型接口, 内置 DAC 数字解码芯片, 并支持 96KHz/24Bit 高清音频 格式, 更好的抗干扰性能, 更棒的兼容性, 更高的解析力, 为你带来更悦耳的音质。 (https://www.oneplus.com/cn)

TT: We've crafted a listening experience that's immersive, vibrant, and extraordinarily detailed, thanks to an advanced internal DAC with high-res audio support. The speakers are fitted with a high-quality film diaphragm that makes voices sound more realistic and immediate, and the flat-wire cables are tangle-free and threaded with tough Karbon fiber.

The ST are dispersed in loose pattern, accompanying the parallel structures to underscore the perfect performance of this type of earphones. As for translating such uncompressed sentence composition, the translator takes the smart approach to reorganize them in accordance with the insider logic to two complete sentences carrying subordinate clauses, making it more customer-friendly.

\section{Conclusion}

Product introductory texts, as one kind of corporate publicity materials displayed on the company's official websites whether in Chinese or English, play a decisive role in attracting potential customers to linger longer on the webpages and switch their underlying demands into real purchase desire.

Nowadays, due to the robust economic development and free business playfield globally, an increasing number of Chinese domestic technology companies expand their presence to overseas markets; the translations of Chinese product introductions to English versions are therefore required if wanting to reach foreign customers. Well-designed technological products demand well-crafted product introductions to highlight the unrivaled features and functions. In addition, expression habits between Chinese and foreigners should be also given attentions in making translation. The product introductory texts in English is for overseas markets, therefore, how to cater for overseas customers seems quite important. In the process of translation of introductory texts, 
translators should do their utmost to highlight the main information of the original text, eliminate language and cultural barriers, and realize the publicity effect. And translators should always bear in mind the principle of purpose so as to flexibly adopt a variety of translation strategies and methods in order to effectively publicize and promote enterprises, to maximize their economic interests, and to achieve the expected objectives of foreign publicity. Under the instruction of the Skopos theory, this paper starts from the C-E translation of product introductory texts on official websites of three domestic leading mobile phone makers and probes into the differences existed in the corresponding two languages. On the basis of case study, it is found that product introductory texts in Chinese prefers more rhetoricexpressions, whereas in English versions, strategies of briefness and conciseness are adopted to point out the main performance and unique design of products, shortening the reading time and facilitating the good customer experience. Therefore, two manipulative guidances, which refine key information and restructure complex information respectively, are raised for reference, in the hope that the C-E translation of product introductory texts on official websites can exert more practical effects on the business activities when presenting to overseas markets.

\section{References}

Lu, X. J. (2012). Textual contrast and English translation of Chinese and American website enterprises. Chinese Translators Journal, (1), 92-97.

Newmark, P. (2001). Approaches to translation. Shanghai: Shanghai Foreign Language Education Press.

Nord, C. (2001). Translating as a purposeful activity_Functionalist approaches explained. Shanghai: Shanghai Foreign Language Education Press.

Sun, X., \& Feng, Q. (2014). Translation of corporate publicity from the perspective of Skopos theory. Foreign Language Research. Tan, Z. (2016). A short history of translation in the west (Revised Ed.). Beijing: The Commercial Press.

Zhang, Y. (2018). English-Chinese translation of drinks advertisements from the perspective of Skopos theory. Overseas English. 